Acta Pó́tica 37•2

julio-diciembre

$2016(21-34)$

Natalia Mendoza Rockwell

Hannah Arendt Center, Bard College

enmendozar@gmail.com

\title{
Narco-mantas o el confín de lo criminal
}

\section{Narcobanners or the Criminal's Confine}

Este artículo recurre a la teoría de actos discursivos de J.L. Austin para realizar un análisis textual de las "narco-mantas", o mensajes públicos firmados por organizaciones criminales. En estos textos breves y fragmentarios se percibe la formación de un discurso político incipiente. Hay en ellos una idea de justicia, la intención de legitimarse frente a un público anónimo, así como intentos frágiles de hablar desde un "nosotros" popular. En la interpretación de la violencia que las narco-mantas buscan imponer está en juego la distinción entre lo criminal y político.

PALABRAS CLAVE: narco-mantas, crimen, política, violencia, actos de habla.

This article draws upon J. L. Austin's speech act theory for a textual analysis of "narco-banners" - public messages signed by criminal organizations. In these short and fragmentary texts, it is possible to perceive the emergence of an incipient political discourse. In particular, these banners display an idea of justice, a search for public legitimacy, and fragile attempts to occupy the voice of a popular "We." The distinction between the criminal and the political is at stake in the interpretation of the violence that these banners attempt to impose.

KEYWORDS: Narco-banners, crime, politics, violence, acts of speech.

Fecha de recepción:4 de noviembre de 2015

Fecha de aceptación: 16 de febrero de 2016 
U

no de los aspectos más desconcertantes de la violencia contemporánea en México es que aparece relativamente desprovista de discurso. A diferencia, por ejemplo, del terrorismo religioso o nacionalista, la violencia en México no emana de una beligerancia ideológica o política. En los medios de comunicación predomina la evidencia material del conflicto —número de cadáveres, tipos de proyectil, casas de seguridad, etc. Los periodistas, agentes del ministerio público y expertos en seguridad se encargan de interpretar esa evidencia y situarla dentro de una narración estándar protagonizada por "cárteles". En este tipo de explicaciones predominan los móviles estrictamente económicos o criminales: principalmente el control de rutas y plazas, y el castigo de la deserción o la traición. El carácter precario y fragmentario del discurso público de los narcotraficantes - así como la preponderancia de las narraciones policíacas - ha ocultado la dimensión propiamente política de la violencia "criminal" en México.

En términos pragmáticos, el crimen organizado y la política son más parecidos de lo quisiéramos suponer. Tienen en común el objetivo de dominar territorios, recursos y poblaciones; ambos tienden a erguirse como un sistema de "intermediación parasitaria" (Sciascia 1986). Tanto las mafias como el Estado ofrecen "protección" a cambio de la exacción de cuotas, premian la lealtad y castigan la traición (Ti1ly 1985; Enzensberger 1974). Son los actos discursivos que acompañan a la violencia, y la serie de procedimientos institucionales en que se inscriben, los que nos permiten trazar la frontera entre lo político y lo criminal, lo legítimo y lo ilegítimo, lo justo y lo injusto.

En México, esa frontera ha perdido nitidez. Las instancias gubernamentales municipales y estatales se han servido de grupos criminales para imponer el control político, y se ha registrado la circulación de cuadros entre las policías municipales y los grupos armados privados. Así mismo, en los últimos años se ha visto la creciente participación de miembros o ex miembros del crimen organizado en la política electoral. Pero hay otra dimensión, quizá más sutil, de este acercamiento que 
tiene que ver con la dificultad que enfrenta el Estado al establecer y defender aquello que en principio lo distingue de otros grupos armados. La dificultad de trazar discursivamente la frontera entre crimen y política. Esta pérdida de autoridad implica que la serie de actos discursivos ${ }^{1}$ que constituyen la práctica cotidiana del Estado - desde otorgar una licencia de manejo hasta resolver una investigación judicial— han ido perdiendo eficacia lingüística: capacidad de afectar el mundo. Implica que las instancias gubernamentales encuentran cada vez más problemas al intentar instaurarse como fuentes de verdades.

A estos factores se sumó, alrededor de 2006, un cambio notable: presuntos miembros de organizaciones criminales comenzaron a participar directamente en los espacios públicos regionales y nacionales — cosa que hasta ese momento había ocurrido muy rara vez. Lo hicieron con mantas atadas a cadáveres, llamadas telefónicas a los medios de comunicación, entrevistas, videos, comentarios en foros de internet, confesiones anónimas y ceremonias públicas de arrepentimiento. ${ }^{2}$ Difícilmente podría decirse que exista una serie de demandas políticas propias del narcotráfico - como lo fue, por ejemplo, la lucha contra la extradición en Colombia. Tampoco parece haber una narrativa social o ideológica coherente y general que enmarque, defina, o dé sentido al sufrimiento. No hay, por ejemplo, un discurso que permita convertir el dolor en sacrificio orientado a la consecución de un bien mayor - como no sea garantizar la sobrevivencia de la siguiente generación: "yo me metí en esto para que mis hijos no se tengan que partir el lomo trabajando". No alcanza del todo a formarse un sujeto político como tal —un "nosotros" bien definido con demandas propias. Aun así, en las esporádicas y de cierta manera fallidas expresiones públicas del narcotráfico alcanza a perfilarse algo que rebasa lo estrictamente económico o criminal y que sugiere dimensiones ideológicas y políticas del conflicto. En este artículo

${ }^{1}$ En este artículo uso el término "acto discursivo" como una traducción del inglés "speech act", tomado de la teoría de la eficacia lingüística de J. L. Austin.

${ }^{2}$ Algunos de los argumentos que desarrollo aquí fueron publicados originalmente en un artículo sobre las nuevas estrategias mediáticas de los narcotraficantes que alcanzaron los medios nacionales en 2010. En particular la entrevista que Julio Scherer hizo al Mayo Zambada y las llamadas telefónicas de "La Tuta". Véase Natalia Mendoza Rockwell. "El narco y los medios", en Letras Libres, 138: 96-98. 
analizo un tipo particular de expresión: los mensajes escritos en pedazos de tela o cartulina que comenzaron a aparecer frecuentemente en la vía pública alrededor de 2006.

Las narco-mantas casi son más medio que mensaje: su forma rebasa en significado a su contenido. En primer lugar porque muchas derivaron su visibilidad pública y fuerza discursiva del hecho de aparecer físicamente asociadas a un cadáver. No sólo es significativo el contexto en que se ubica la manta, también su forma misma. La gran mayoría están escritas con spray, con abundantes faltas de ortografía, insultos y enunciados ininteligibles. La excepción a esta norma han sido las mantas de las organizaciones criminales michoacanas, concretamente La Familia y Los Caballeros Templarios, que solían estar escritas en un estilo mucho más institucional y manufacturadas en comercios especializados. Es notable que muchas mantas estén escritas en letras negras y rojas, lo que sugiere una extraña reminiscencia de la tradición sindical. Las narco-mantas, como género textual, se sitúan en un rango que va de la "pinta" (o grafiti) al comunicado sindical. En este artículo hablaré por separado de lo que, para facilitar el análisis, llamo "narcopintas" y "narco-comunicados".

\section{Narco-pintas}

Las narco-pintas, como las flechas o los semáforos, son signos indexicales o indicativos (Pierce 1998). Es decir, su significado es indisociable de su contexto físico, en este caso la muerte que comentan. En eso se parecen a la adjudicación verbal de un acto terrorista: su objetivo central es dictar la interpretación de un hecho violento y apropiarse de su fuerza simbólica. Por ejemplo, éste es el texto de una manta que apareció en Culiacán en octubre de 2008, en el mismo lugar en el que una semana antes se había encontrado el cadáver al que hace referencia. El texto está escrito en primera persona y se lee como una suerte de encarnación póstuma de la voz del muerto que explica el lugar y motivos de su muerte: 
Ya no me busquen en Tamaulipas, el Mayo, el Chapo y el Nacho Coronel me traisionaron y me mataron afuera del estadio Banorte en Culiacan.

De acuerdo con J. L. Austin, uno de los errores centrales de la filosofía analítica ha sido la idea de que la función fundamental del lenguaje es representar la realidad a través de enunciados que pueden determinarse como falsos o verdaderos. En realidad, argumenta el autor, la mayor parte de los enunciados que usamos no dicen cosas sobre el mundo sino que llevan a cabo acciones, hacen cosas. Ese tipo de enunciados son los que Austin llama "actos discursivos realizativos" — una traducción desafortunada del inglés "speech acts" o "performative speech acts". Los ejemplos de actos discursivos van de una declaración de guerra a un juramento, o una ceremonia de matrimonio. El enunciado "los declaro marido y mujer", por ejemplo, cumple con la característica fundamental de los actos discursivos, pues lleva a cabo una acción en el mundo al transformar el estatus de los involucrados. Los actos discursivos no se pueden juzgar en términos de verdad o falsedad, sino de eficacia lingüística. Los actos "afortunados" — mi traducción del inglés felicitous - son aquellos en los que la acción se logra. Los actos discursivos desafortunados — infelicitous - son aquellos en que la acción se frustra, el acto resulta inválido (Austin 1975).

La mayor parte de las narco-pintas llevan a cabo dos tipos de acciones discursivas. La primera es la adjudicación de la violencia. Esto implica no simplemente la imposición de una interpretación del hecho violento, sino también la apropiación del valor simbólico de esa muerte. Esta apropiación es la condición para que se lleve a cabo de manera eficaz la segunda acción característica de las narco-pintas: la amenaza. Ambas acciones discursivas, la adjudicación y la amenaza, derivan su significado y su eficacia lingüística del hecho de aparecer junto a un cadáver. Como hemos dicho, las narco-pintas son signos indexicales: señalan un suceso físico en el mundo y lo comentan, fuera de ese contexto pierden todo su significado. Por ejemplo, el siguiente mensaje apareció el 27 de noviembre de 2015 junto con ocho cadáveres en la comunidad de Cosolapa, Oaxaca: "Esto le va a pasar a toda la gente que me man- 
des. Atte: el Chiquis". ${ }^{3}$ El "esto" de este mensaje es un índice, una flecha que señala algo en el mundo y no tendría el mismo significado si no apareciera físicamente contiguo a ocho cadáveres. Las narco-pintas son etiquetas que se sobreponen a la evidencia física de la violencia para apropiarse su valor simbólico.

La otra característica de las narco-pintas es que, a diferencia de los narco-comunicados, no se dirigen al público en general, sino a personas o grupos particulares. Leerlas es un poco como escuchar una conversación ajena. A pesar de dirigirse a un destinatario particular, estos mensajes también se sirven de los medios de comunicación y de alguna manera suponen la existencia de un tercer espectador. Su fuerza radica precisamente en el hecho de aparecer en el espacio público como la filtración de un secreto. El efecto de veracidad o autenticidad que puedan causar depende de que sean leídos como la aparición no mediada de una voz que generalmente se mantiene oculta. El siguiente ejemplo ilustra este punto: "Sigues tú y tus achichincles los nerines por andar matando mujeres, las mujeres se respetan culero".

Este es un mensaje privado, va dirigido a un "tú" que presuntamente se dará por aludido. Sin embargo, al nombrar la identidad del grupo al que se está dirigiendo, "los nerines", el mensaje también se dirige de manera indirecta a un tercer espectador que necesita más información. Finalmente, el mensaje revela ante un público que la víctima encontrada junto a la manta es alguien que ha matado mujeres. De esta forma se dibuja, incluso en un texto así de corto y precario, una idea de justicia. En general, la idea de justicia de las narco-pintas se centra en dos asuntos. El primero es la distinción entre tipos de víctimas. Están, por un lado, los hombres armados - ya sea miembros de grupos delictivos rivales, policías, o ejército- $\mathrm{y}$, por el otro, la familia, las mujeres, la sociedad, o los inocentes. El segundo aspecto es la abundancia de referencias a la traición y la duplicidad como los males morales de mayor gravedad.

De una forma u otra, las narco-pintas siempre dicen: "Esto es un castigo merecido". El caso más emblemático de este tipo de discurso

3 Tomás Martínez. "Ejecutan a ocho personas en la Cuenca de Oaxaca; dejan narcomensaje", en <http:/www.noticiasnet.mx/portal/oaxaca/roja/accidentes/315292-ejecutan-8-personas-cuenca-oaxaca-dejan-narcomensaje $>$. 
es la idea de "justicia divina" que la Familia Michoacana utilizó. En septiembre de 2006, por ejemplo, un comando armado entró a un salón nocturno de Uruapan, tiró cinco cabezas humanas y dejó el siguiente mensaje en una cartulina: "La familia no mata por paga. No mata mujeres. No mata inocentes. Solo muere quien debe morir sépanlo toda la gente, esto es justicia divina". ${ }^{4}$ Este mensaje es distinto de los anteriores: es propaganda, se dirige al público en general y busca legitimar las acciones de un grupo delictivo en términos políticos. No explica la violencia como resultado de rivalidades o "traiciones" sino como limpieza —_solo muere quien debe morir". Este mensaje es mucho más político que criminal.

\section{Narco-comunicado}

En los narco-comunicados se percibe más claramente la influencia de la retórica de las organizaciones populares. Con frecuencia están escritos con letras rojas y negras - como las mantas sindicales. Una de sus características más importantes, que las convierte en una forma de discurso propiamente político, es que se dirigen simultáneamente al "pueblo" y a "las autoridades" o al "Sr. Presidente". En ese sentido, más que realizar una amenaza, expresan alguna clase de agravio o demanda.

La manta "de despedida" que los Caballeros Templarios hicieron pública al final del mandato de Felipe Calderón es uno de los ejemplos más notables de este estilo. Al título en rojo, "Mensaje para el señor Felipe de Jesús Calderón Hinojosa", le sigue un mensaje largo y abigarrado en color negro:

Señor presidente le queremos decir atraves de estas mantas ya que no tenemos otro medio para comunicarnos que nunca estuvimos de acuerdo en la forma en que nos trato, su intención tal vez era buena pero no la forma. Sin embargo aun con el dolor humano que nos causo y con las heridas que siguen latentes le queremos decir que aprendimos mucho

4 “Arrojan cinco cabezas en un centro nocturno de Uruapan", en La Jornada, 7 de septiembre de 2006, en <http://www.jornada.unam.mx/2006/09/07/index.php?section= estados\&article $=037 \mathrm{n} 1$ est $>$. 
pues tambien nosotros como pueblo rebelde o muy heroico reconocemos que tambien a sus PFP's les causamos heridas y muy merecidas. Nosotros como pueblo o hermandad lo quisimos respetar pero usted nunca volteo la mirada hacia nosotros en buen plan otra cosa hubiera sido para Michoacan si usted con su embergadura y potestad que manejo hubiera tratado con amor a su pueblo y justicia verdadera. Ante todo y por todo nos disculpamos y como ya no lo vamos a tener en diciembre como nuestro gobernante le deseamos a usted, a su familia y a su gabinete que le vaya como dijo Vicente Fernandez...ojala que le valla bonito.

C.T.G.M. Caballeros Templarios Guardia Michoacana.

Esta manta de los Caballeros Templarios pertenece a un género discursivo mucho más sofisticado que las anteriores. No apareció asociada con cadáveres, sino con un acto político: la última visita de Felipe Calderón al Estado de Michoacán. Su sentido va más allá de la adjudicación de la violencia o la amenaza. El sujeto que habla en esta manta - el nosotros de "nosotros como pueblo o hermandad", por ejemploes un sujeto político. Hay también una peculiar mezcla de solemnidad y burla. El texto, por ejemplo, remata citando una canción popular, "ojalá que te vaya bonito". Ese final parece inducir una lectura irónica de todo el texto, indica que debe ser leído como una forma de escarnio público.

El texto de la manta comienza con una reflexión meta-textual sobre su medio de expresión: "atraves de estas mantas ya que no tenemos otro medio para comunicarnos". De manera muy sutil, esa introducción sitúa al sujeto colectivo que habla en una posición de exclusión, de carencia, incluso de victimización. Ese enunciado usurpa la autoridad moral y la legitimidad política de "los sin voz". En el mismo tono, el siguiente enunciado emite un juicio sobre las acciones del presidente y expone un agravio, "el dolor humano que nos causó". Lo único que interrumpe esta lógica de exposición de agravios, que sería característica de una organización civil, es el reconocimiento de que las heridas fueron mutuas y "merecidas".

A continuación viene un momento extrañísimo: ¿de qué universo lingüístico salió este "aprendimos mucho"? ¿Cómo se coló en una narco-manta? La frase evoca quizá los discursos de celebraciones 
sociales - XV años, bodas o graduaciones - incluso remite al género de habla característico de las rupturas románticas. ¿Es irónica esa cursilería? En todo caso, el enunciado tiene el efecto de solidificar la identidad de la organización social, pues "aprendimos mucho" supone acumulación y continuidad. De esta forma, la organización que habla se presenta como más estable, más continua que el mandato presidencial. El presidente se va, pero ellos se quedan, se dan el lujo de despedirlo y de vanagloriarse de su aprendizaje.

El texto de la manta contiene también un contrafactual - "otra cosa hubiera sido si"- que sirve de introducción a una idea del buen gobierno. Este ideal de gobierno se caracteriza por "el amor al pueblo y justicia verdadera". Un tema recurrente en las narco-mantas, y en el universo moral y político que representan, es la distinción constante entre la verdad y las apariencias, en este caso entre "la justicia" y "la justicia verdadera". Las mantas constantemente afirman la falsedad, la hipocresía y la duplicidad de la esfera pública. Todo lo que vemos y decimos en público, especialmente en la política, es simulacro, teatro. El "nosotros" de esta manta se arroga a sí mismo el derecho de hablar desde un nivel de verdad superior.

Los narco-comunicados, a diferencia de las narco-pintas, no son mensajes privados hechos públicos. Incluso si esta manta se dirige en segunda persona al presidente, su intención es claramente pública, busca apelar y seducir al público en general, al espectador anónimo. Este gesto discursivo es una de las diferencias importantes entre crimen y política. En Publics and Counterpublics, Michael Warner define un público como una forma de "sociabilidad entre extraños" que resulta de la circulación de mensajes que, en su escritura, asumen la existencia de dicho público. Por esta razón, Warner afirma que un público tiene una estructura circular: comienza a existir en el momento en que alguien se dirige a él, pero para dirigirse a él hay que suponer que existe. El círculo se cierra cuando el espectador se siente interpelado o aludido por el apelativo del enunciado. Por ejemplo, al dirigirme a "los padres de familia" asumo la existencia de dicho público, pero éste sólo comienza a existir en el momento en que un "padre de familia" se siente interpelado por mi apelativo y mi mensaje (Warner 2006). 
Una de las características más interesantes de los narco-comunicados es que la posición del remitente y el destinatario son inestables. Es decir, la posición desde la que se habla y el público que se busca interpelar no consiguen definirse del todo. Esto es particularmente claro cuando se analiza el uso de los pronombres "nosotros", "ustedes" y "ellos" en el texto, pero no se limita al uso pronominal. Tiene que ver con algo más amplio que podríamos llamar "voz", las narco-mantas no sólo cambian de pronombre constantemente sino que son "polifónicas" (Bakthin 1984). Por ejemplo: "Si quieren que se acabe la inseguridad en el país. Ya dejen de proteger al Chapo Guzman, al Mayo Zambada, y a los Michoacanos asi como también a los Mandatarios Partidistas que son igual de Narcos que ellos ya que llevan: 40 años de Narcomandatarios".

La primera oración se dirige a un "ustedes" que puede ser el gobierno, la sociedad civil o cualquiera que se identifique con el deseo descrito. La segunda oración es un anfibio. "Ya dejen de proteger" indica que el "ustedes" al que apela la manta son las autoridades gubernamentales, puesto que son las únicas en posición de "proteger". Después, la manta da el nombre de los "protegidos" — miembros del cártel de Sinaloa y las organizaciones michoacanas. Hasta este momento parece obvio que el texto está escrito desde la perspectiva de un miembro de una organización criminal rival que ofrece al gobierno y al público en general el fin de la inseguridad a cambio de la igualdad de condiciones para todas las organizaciones delictivas. Sin embargo, hacia el final de ese enunciado - "también a los mandatarios partidistas que son igual de narcos que ellos" - el texto prácticamente se extrae de su propia voz para encarnarse en la voz de la "sociedad civil" o del "pueblo" que habla de los narcos en tercera persona y se queja de los "narcomandatarios". Escuchar a una organización delictiva quejarse de los "40 años de Narcomandatarios" es como escuchar a un líder sindical quejarse de las prácticas clientelares. Me parece que ese cambio de voz fue dictado por el género. Es decir, que una narco-manta que se dirige al público y critica al gobierno, lo hace siguiendo las reglas estilísticas del género en que se hacen ese tipo de denuncias: usando la voz de la "sociedad civil". Un ejemplo más claro: 
SI QUIERES QUE TERMINE LA ANARQUIA DEL NARCO POR QUE TU GOBIERNO NO ATACA A NARCOS COMO JOAQUIN EL CHAPO GUZMAN, ISMAEL EL MAYO ZAMBADA, IGNACIO NACHO CORONEL, OSCAR NANA VALENCIA, EL REY ZAMBADA Y MICHOACANOS NARCOS DE 30 AÑOS DE EXISTIR LOS CUALES TIENEN 9 AÑOS QUE TU GOBIERNO LOS PROTEGE LO CUALES GOZAN DE IMPUNIDAD ABSOLUTA. LA CIUDADANIA ESTAMOS CANSADOS DE ESTO.

El mensaje establece primero una diferencia por medio del uso pronominal — con el tu de "tu gobierno"- entre tres grupos, los narcos ("nosotros"), la "sociedad civil" o "el pueblo" ("ustedes"), el gobierno ("ellos"). Sin embargo, la nitidez de esta distinción entre los tres actores se diluye en el segundo enunciado. Esta manta denuncia la misma situación que la anterior: el gobierno protege al Cártel de Sinaloa y a las organizaciones michoacanas, "hace treinta años que existen y hace nueve que tu gobierno los protege". Por lo tanto, el gobierno es un narcogobierno, lo cual complica la distinción entre el "nosotros" y el "ellos" original. En la última oración se da nuevamente un cambio radical en la voz del texto. Los narcos hablan desde la perspectiva de la ciudadanía: "la ciudadanía estamos cansados de esto".

Los narco-comunicados, en tanto que actos discursivos, intentan definir fronteras, establecer identidades o categorías, pero el intento se ofusca con frecuencia a medio camino. Parece un detalle sin importancia, pero es un punto crucial. La operación fundamental del discurso político es precisamente la formación de un "nosotros" y un "ellos" (Arendt 1963; Laclau 2005), o la diferencia entre "amigos" y "enemigos", de acuerdo con Schmitt (1996). Discursivamente, el crimen organizado busca identificarse con la sociedad civil — con "el pueblo heroico" agraviado, en el ejemplo de los Caballeros Templarios- y denunciar al "narco-gobierno". Pero esa denuncia paradójicamente lo implica en aquello de lo que busca disociarse.

\section{Conclusiones}

Es difícil pensar en una actividad económica en el México contemporáneo que haya transformado el paisaje social, sobre todo en el mundo 
rural, de manera más radical que el tráfico de drogas y la extorsión. No hay otro proceso económico o político que haya provocado cambios tan profundos en la distribución de los recursos y de la fuerza en algunas regiones como el crimen organizado. Pocas veces se ha visto a los miembros de las clases marginadas apoderarse de recursos equiparables e incluso mayores a los de las viejas clases terratenientes de manera tan veloz (Mendoza 2007). Pocas veces se ha visto a regiones periféricas, como es el caso de los ranchos de la sierra michoacana, convertirse en el centro político de prácticamente todo un estado (Le Cour Grandmaison 2015). El ideal central de la "narco-cultura" es el de la movilidad social, sobre todo la individual, pero a veces también la colectiva.

El costo en vidas humanas ha sido el de una guerra civil. Quizá no la reconocemos como tal porque el vocabulario político que heredamos del siglo diecinueve no tiene las palabras para nombrar los actores, las fuerzas, o los principios de esta guerra. No hay actos discursivos codificados, como las declaraciones de guerra o los congresos constituyentes del pasado, que permitan refundar la diferencia entre lo criminal y lo político. No hay una filosofía de la historia que nos permita convertir esta "bola" en revolución. Tal vez por esa razón, las narco-pintas alcancen sólo a escribirse como conversación privada hecha pública, como la exhibición de un secreto. Se dirigen al público de manera oblicua, ladina, ocultándose. Paradójicamente, ese carácter de secreto revelado que tienen las narco-pintas les da algo que no tiene el discurso estatal: hace que les creamos, que las consideremos "auténticas".

En los narco-comunicados, por lo contrario, el crimen organizado se dirige al público siguiendo las normas estilísticas del género y buscando usurpar el "nosotros" del "pueblo heroico" o "la ciudadanía" — los grandes protagonistas políticos de los últimos dos siglos. Esa operación lingüística, sin embargo, aparece en las narco-mantas como atrofiada, contradictoria y titubeante. La ambigüedad de estos textos, la visible confusión de actores y formas de violencia que en ellos se lee, no se explica simplemente por un mal manejo del lenguaje escrito. Tiene que ver con procesos más amplios, como el acercamiento entre las formas de dominación estatales y criminales. Tiene que ver también con un creciente desfase entre el vocabulario político del que disponemos y el tipo de procesos sociales que estamos presenciando. 


\section{BIBLIOGRAFÍA}

Arendt, Hannah. On Revolution. New York: Penguin Classics, 1963.

"Arrojan cinco cabezas en un centro nocturno de Uruapan", en La Jornada. Ciudad de México, 7 de septiembre, 2006. Artículo en línea disponible en $<$ http://www.jornada.unam.mx/2006/09/07/index.php?section=estados\& article $=037 \mathrm{n} 1$ est $>$ [fecha de consulta: 17 de enero de 2016].

Austin, J. L. How to Do Things with Words. Cambridge: Harvard University Press, 1975.

Bakthin, Mikhail. Problems of Dostoevsky's Poetics. Minneapolis: University Minnesota Press, 1984.

Enzensberger, Hans Magnus. Politics and Crime. Nueva York: The Seabury Press, 1974.

Laclau, Ernesto. On Populist Reason. New York: Verso, 2005.

Le Cour Grandmaison, Romain. "The Structuring of Drug Cartels: From Political to Criminal Intermediation in Michoacan", Ponencia presentada en el Americas Seminar. Columbia: University, November 2015.

Martínez, Tomás. "Ejecutan a ocho personas en la Cuenca de Oaxaca; dejan narco-mensaje". Artículo en línea disponible en <http://www.noticiasnet.mx/ portal/oaxaca/roja/accidentes/315292-ejecutan-8-personas-cuenca-oaxacadejan-narcomensaje $>$ [fecha de consulta: 17 de enero de 2016].

Mendoza Rockwell, Natalia. Conversaciones en el Desierto: Cultura, Moral y Tráfico de Drogas. México: Centro de Investigación y Docencia Económicas, 2007.

Pierce, Charles Sender. "What is a Sign?", en The Essential Peirce: Selected Philosophical Writing Vol.2. Bloomington: Indiana University Press, 1998.

Schmitt, Carl. The Concept of the Political. Chicago: The University of Chicago Press, 1996.

Sciascia, Leonardo. "Prefacio", en Fabrizio Calvi. El misterio de la Mafia: La organización al descubierto. Barcelona: Gedisa, 1986.

Tilly, Charles. "War Making and State Making as Organized Crime", en Peter Evans, Dietrich Rueschemeyer y Theda Skocpol, Bringing the State Back. Cambridge: Cambridge University Press, 1985.

Warner, Michael. Publics and Counterpublics. New York: Zone Books, 2006. Natalia Mendoza Rockwell 
Natalia Mendoza Rockwell

Doctora en antropología por la universidad de Columbia y licenciada en Relaciones Internacionales por El Colegio de México. Ha hecho trabajo de campo sobre narcotráfico, violencia y política en Sonora desde 2004. Es autora del libro Conversaciones del desierto: Cultural, moral y tráfico de drogas (CIDE, 2007). A partir de 2010, ha investigado las formas de representación y discurso político en Malí. Sus principales temas de investigación son el crimen, la política, la filosofía del lenguaje y la historia intelectual de África, Latinoamérica y el Caribe. 